\title{
Modelling upper respiratory tract diseases: getting grips on host-microbe interactions in chronic rhinosinusitis using in vitro technologies
}

\author{
Charlotte De Rudder ${ }^{1}$, Marta Calatayud Arroyo ${ }^{1}$, Sarah Lebeer ${ }^{2}$ and Tom Van de Wiele ${ }^{1 *}$
}

\begin{abstract}
Chronic rhinosinusitis (CRS) is a chronic inflammation of the mucosa of the nose and paranasal sinuses affecting approximately $11 \%$ of the adult population in Europe. Inadequate immune responses, as well as a dysbiosis of the sinonasal microbiota, have been put forward as aetiological factors of the disease. However, despite the prevalence of this disease, there is no consensus on the aetiology and mechanisms of pathogenesis of CRS. Further research requires in vitro models mimicking the healthy and diseased host environment along with the sinonasal microbiota. This review aims to provide an overview of CRS model systems and proposes in vitro modelling strategies to conduct mechanistic research in an ecological framework on the sinonasal microbiota and its interactions with the host in health and CRS.
\end{abstract}

\section{Background}

The upper respiratory tract is one of the primary body sites of contact with the outside environment and its physical, chemical and infectious agents. It is therefore unsurprising that upper respiratory tract infections are a major health concern. Chronic rhinosinusitis (CRS) is a disease that affects $10.9 \%$ of the adult population in Europe [1]. It is defined as chronic inflammation (>12 weeks) of the nasal and paranasal sinus mucosa, characterised by two or more symptoms, one of which should be either nasal obstruction, congestion or nasal discharge and is further identified by facial pain, pressure and/or reduction or loss of smell [2]. Supportive objective evidence includes rhinoscopic or endoscopic findings of polyps and/or purulent discharge and/or oedema or mucosal obstruction in the middle meatus and/or ethmoid region. Next to this, a CT scan can demonstrate mucosal changes within the paranasal sinuses [3]. CRS patients are typically classified in two major clinical subgroups or phenotypes based on the presence or absence of nasal polyps (NP) (respectively

\footnotetext{
* Correspondence: Tom.VandeWiele@UGent.be

${ }^{1}$ Center for Microbial Ecology and Technology, Faculty of Bioscience

Engineering, Ghent University, Coupure Links 653, B-9000 Ghent, Belgium Full list of author information is available at the end of the article
}

CRSwNP and CRSsNP) [2, 3], although endotypes and clusters can be distinguished within these subgroups, based on inflammatory profiles $[3,4]$. Despite the high prevalence of CRS, there is no consensus about the aetiology of the disease [5]. In recent years, however, understanding of the importance of the sinonasal microbiome in this disease is emerging [6-10]. The view that a respiratory microbiota in equilibrium contributes to host health by immune priming and provision of colonisation resistance, similar to the gut microbiome, gains interest [11-14]. Analogously, a disrupted airway microbiota could decrease resistance to pathogen infection and overgrowth and result in inflammatory responses $[10,15,16]$. Culture-independent techniques, such as next-generation sequencing, have enabled in-depth study of the differences in community structure in healthy and CRS upper respiratory tracts [7, 17-25].

In addition to in vivo human research, mouse, rabbit and sheep models to further study CRS have been developed, despite the ambiguous aetiology of the disease (as reviewed in Shin [26]). Current animal models are either based on infection with specific bacterial or fungal pathogens $[11,27]$ or on immunostimulation causing allergic rhinosinusitis [28, 29]. In vivo animal models of CRS can be used to study more complex immune responses, 
pathogen invasion in a natural microbiota context, and histologic and systemic effects $[11,29,30]$ than in vitro models. Differences in sinus morphology, disease development, microbiome, pathogens and immune response between humans and test animals should be taken into account in the interpretation of results [26]. Although in vivo observations and intervention studies supply valuable information, there is a need for in vitro models according to the $3 \mathrm{R}$ principle (refinement, reduction, replacement). Adequate in vitro models mimicking the in vivo environment allow initial testing of numerous conditions such as effects of pathogen or allergen exposure on the host, influence of physical changes in the host microenvironment on both host and microbiota or exploration of the potency of probiotics or biologicals in disease prevention and/or control. Subsequently, the most promising settings can be selected for animal studies, hereby refining the in vivo research and reducing the required number of laboratory animals [31]. To study host-microbe interactions in health and disease, systems mimicking the host mucosal environment and its complex microbiota in a reproducible manner have recently been developed, i.e. in our research group, for the human gastrointestinal tract [32-34] and the oral cavity [35]. In order to study airway diseases and mechanistically understand hostmicrobe interactions, the development of similar, representative models for the respiratory tract is essential.

In this review, a short overview of the main characteristics of the sinonasal CRS environment is given (the reader is referred to Hamilos [36], Hamilos [37], Scheckenbach and Wagenmann [38] and Stevens et al. [39] for reviews on the immune response in CRS and to Mahdavinia et al. [40] and Hoggard et al. [41] for the microbiota in CRS). Furthermore, we aim to review the current methods to study airway host-microbe interactions in vitro and propose in vitro modelling strategies to conduct mechanistic research in an ecological framework on the sinonasal microbiota and its interactions with the host in health and CRS.

\section{The sinonasal microenvironment}

\section{Epithelial lining of the sinonasal cavities}

The nose and paranasal sinuses (the maxillary sinuses, the ethmoid sinuses, the sphenoid sinuses and the frontal sinuses) form a specific niche within the human body. They consist of a unified system of skin and mucosal surfaces and form the primary site of contact with inhaled air in the respiratory tract. The nostrils and anterior nares are lined with keratinized stratified squamous epithelium and contain serous and sebaceous glands [42]. The surfaces of the nasal cavity and the paranasal sinuses on the other hand are carpeted with typical respiratory epithelium with pseudostratified ciliated columnar epithelium and are characterised by the presence of basal cells and mucin-secreting goblet cells [43]. The activity of the goblet cells results in the presence of a mucus layer, which is continuously removed by mucociliary clearance and subsequently collected in the nasal cavity.

\section{CRS-associated sinonasal microenvironment}

The inflammatory state of the sinonasal epithelium of CRS patients renders their sinonasal cavities different from those in healthy individuals. Inflammatory tissue is often characterised by hypoxia, a low level of oxygen in tissues, typically occurring when available oxygen levels are between 0.5 and 3\% [44], and altered interleukin (IL) secretion (e.g. IL-13), both factors inducing goblet cell hyperplasia [45, 46], mucus hypersecretion [46-48] and increased mucin expression [45-47]. These factors result in increased thickness of the mucus layer and mucostasis, a lack of mucus flow resulting in mucus accumulation. Furthermore, the diameters of the ostia, the openings connecting the sinus cavities with the nasal cavity, can be severely reduced or completely obstructed. Leung et al. [49] found uni- or bilateral osteomeatal complex obstruction in $64.4 \%$ of CRSsNP patients $(n=$ $144)$ and in $75.0 \%$ in CRSwNP patients $(n=123)$, from a patient population requiring surgery for CRS. This causes a reduction in sinus aeration (hypoxia) and an additional accumulation of mucus and other sinus secretions. Hypoxia itself induces tissue remodelling (e.g. polyposis) and upregulation of inflammatory pathways $[44,50]$. Hypoxia can decrease the expression of antimicrobial proteins [51], facilitate the growth of anaerobic bacteria [52] and eventually result in increased inflammatory tissue damage [53].

An improper epithelial barrier function, with increased paracellular permeability and decreased tight junction expression, has also been linked to the CRS disease phenotype [54-56]. Possibly due to the impaired barrier function of damaged epithelium, CRS patients have significantly increased nasal airway surface liquid (ASL) glucose concentrations compared to control patients [57]. In contrast, carbon sources, such as glucose, are actively depleted from ASL by healthy airway epithelium [58]. The increased glucose concentration in CRS ASL might facilitate bacterial growth by increased carbon source availability and reduced antimicrobial protein secretion via a bitter taste receptor (type 2 receptor)-mediated pathway [57]. Bitter taste receptors have recently been identified as players in innate sinonasal immunity against bacterial invasion and biofilm formation through nitric oxide production, and increased ciliary beating upon activation by bacterial quorum sensing molecules and their (dys)function could play a role in CRS recalcitrance [59-62].

The production of antimicrobial proteins (AMP), such as lysozyme, lactoferrin, PLUNC (palate, lung, and nasal 
epithelial clone) proteins and defensins, and the secretion of immunoglobulin A (IgA) are protective mechanisms in the upper respiratory tract (URT) [63]. Altered profiles of these compounds have been associated with CRS pathogenesis. Decreased short PLUNC-1 (SPLUNC-1) has been observed in CRSwNP [64] and CRSwNP polyp tissue, compared to control tissues [65]. Decreased SPLUNC-1 also appeared to be associated with positive Pseudomonas aeruginosa bacterial colonisation and poor clinical outcomes [64, 66]. It has been demonstrated in nasal polyp cultures at air-liquid interface (ALI) that IL-13 has a downregulating effect on SPLUNC-1 expression [67]. Next to AMP, the epithelium has the ability to produce a broad array of cytokines and chemokines to modulate immune responses towards both commensal and invading microorganisms. Various studies have yet shown altered cytokine profiles in cell cultures from CRS patients compared to non-CRS controls [54, 68, 69]. Distinctive cytokine profiles are observed between CRSwNP and CRSsNP [2] and the different endotypes therein [3, 4]. CRSsNP appears to display a $\mathrm{T}_{H} 1$-skewed cytokine profile, while CRSwNP is more commonly characterised by a $\mathrm{T}_{H} 2$ response and eosinophilic NP in Caucasian patients [70, 71]. In contrast, an interferon- $\gamma$ (IFN- $\gamma$ )- and/or IL-17-biased profile with neutrophilic NP appears more typical in Asian
CRSwNP patient populations [72]. An overview of the most outstanding parameters of the CRS mucosal environment is presented in Fig. 1.

\section{Bacterial microbiome of the sinonasal cavities Composition of the sinonasal bacterial communities} In recent years, interest in the sinonasal cavity microbiome has increased, and the use of molecular methods to study microbial communities has enabled characterisation of the sinonasal microbiota, bypassing cultivation bias [7, 17-25]. They show that the sinonasal microbiota is very diverse and highly variable between individuals $[7,17-25]$ and indicate a high temporal variability within individuals [17].

The microbiome of the sinonasal cavities appears to be characterised by the high relative abundance of three phyla: Firmicutes, Actinobacteria and Proteobacteria [17-19, 25]. Corynebacterium and Propionibacterium species have been found at high abundances in most individuals [17, 18, 24, 25, 73]. The species richness in the nasopharynx of healthy westernised adults varied greatly between subjects and time points and has been estimated (Chaol index) to be between 6 and 110 (average $=50, n=97$ ) [17]. Yan et al. [25] reported estimated species richness (Chao1 index) in the anterior naris,

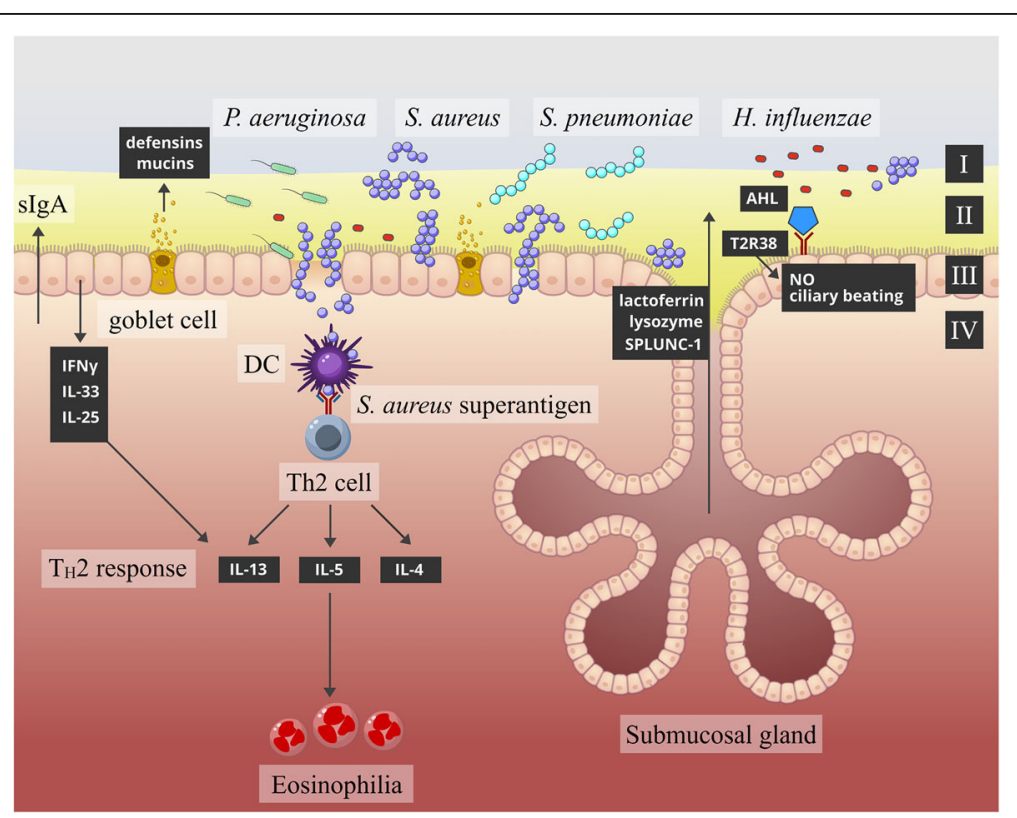

Fig. 1 Schematic representation of CRS tissue. A proposed model for the changes of the sinonasal environment during CRS. Increased mucus production and/or goblet cell hyperplasia can result in a mucus layer with increased thickness (I). Changes in sinus microbiota can be observed, more specifically the abundances of CRS-associated pathogens S. aureus, P. aeruginosa, S. pneumoniae and H. influenza. Proposed changes involve decreased epithelial integrity (III: defective epithelial barrier function), with increased glucose concentrations in the airway surface liquid (II), decreased recognition of acyl-homoserine lactones by T2R38 receptors, altered cytokine production and decreased antimicrobial protein and immunoglobulin production that occur in CRS compared to healthy tissue. These changes potentially provide an environment that promotes pathogenic bacterial growth and invasion of the epithelial barrier (IV), resulting in chronic inflammation. S. aureus has the ability to produce a super-antigen, which evades conventional immune response and directly elicits eosinophilia and a $T_{H} 2$-skewed immune response (IL-5, IL-13, IL-4), whereas IFN- $\gamma$ induces a $T_{H} 1$-skewed immune response (figure adapted from Mahdavinia et al. [40]) 
middle meatus and sphenoethmoidal recess between 200 and $400(n=179)$. Healthy sinonasal cavities are relatively nutrient-poor niches in the human body for microbial colonisation [74]. As a result, the bacterial density in the sinonasal cavities is estimated to be at least 10 times lower in comparison to the oral cavity (based on 16S copy numbers in sample) [75].

\section{Dysbiosis in CRS}

Dysbiosis of the bacterial community composition, a disruption of the equilibrium and mutualistic relationships between commensal microorganisms mutually and with the host epithelium, has been implied in the aetiology, pathogenesis and recalcitrance of CRS [9-11, 13, 41]. Mackenzie et al. [10] suggested that the bacterial community associated with CRS is dysbiotic and that the ecological networks in these communities are fragmented. They proposed Burkholderia and Propionibacterium as keystone genera in healthy ecological networks [10]. It remains however unclear whether an imbalance in the local microbiota and/or colonisation by pathogenic species elicits an immune response and results in a chronic inflammatory condition or whether an initial inflammation of the epithelium and/or sinus obstruction provides a platform for sustained bacterial dysbiosis, resulting in a CRS phenotype $[6,37,63]$. In addition, the interplay between the (inadequate) host immune response and the microbiota (in a state of dysbiosis) might also be explanatory for the CRS phenotype [76]. Apart from the causality of dysbiosis for CRS, the sinonasal microbiome could play a role in the self-perpetuation of the disease and be decisive in the therapeutic outcome. Several studies have suggested that the diseased CRS sinonasal environment is characterised by a higher bacterial load and/or a lower diversity. However, contradictory results have been observed. Several research groups [11, 20, 72, 77] detected no difference in bacterial load between CRS and non-CRS patients, although a reduced diversity was observed in CRS patients. Contrarily, a higher bacterial load [7,73] and increased diversity [6] were observed in other studies comparing (refractory) CRS patients to non-CRS controls. Aurora et al. [6] analysed nasal lavage fluid of CRSwNP, CRSsNP and control patients, which, contradictorily to the observations of Aurora et al. [6], revealed a lower species diversity and an increased bacterial burden in CRS patients compared to controls. By comparing the bacterial load in CRS and non-CRS patients, it has been proposed that the bacterial load in the sinonasal cavity is defined, but that the community composition is rather influenced by conditions such as illness and antibiotic use [11, 72, 78]. The lack of consensus on a specific bacterial profile associated with CRS could be a result of the diversity of DNA collection method and the sampling place within the sinonasal environment. Furthermore, a history of antibiotic use in CRS, the phenotype and severity of the disease, and disease subgroups can be confounding factors. Typically, only small patient and control cohorts (e.g. respectively 9 and 6, [20]) can be used for sinus microbiota sampling due to the requirements to stay off antibiotics for 4 weeks prior to surgery and the difficulty of sampling via endoscopic sinus surgery [20]. The most important confounding factors are antibiotic and corticosteroid use in case of CRS, as these are known to severely impact microbiota diversity [22, 79]. Biswas et al. [20] selected CRS patients that were off antibiotics for 4 weeks prior to surgery. The impact of this selection criterion is however unclear, as Feazel et al. [22] reported a significant reduction in species richness and evenness as a result of antibiotic use 12 weeks prior to sampling. The CRS patients sampled by Abreu et al. [11] all had a history of antibiotic use.

\section{Biofilm formation in CRS}

Next to their community composition, the physiological state in which bacteria are present on the mucosal surface has importance in the CRS context. Biofilm formation is a commonly observed survival strategy among microorganisms in which a microbial community is enclosed in an exopolymer matrix of their own making and attached to a surface. Biofilms can have a complex structural organisation, which enables intense interactions between the composing organisms. They provide protection from physicochemical environmental stressors such as shear stress and harmful compounds. Especially relevant in a healthcare context is the enhanced antibiotic resistance observed in biofilms, which can be a factor of 1000 higher than the same species in planktonic form [80, 81]. Chronic disease, extreme resistance to antibiotic treatment and repeated acute exacerbations are characteristic of biofilm-mediated diseases and are also observed in CRS patients [70, 82].

Biofilm formation in CRS can be confirmed by electron or laser microscopy on tissue biopsies $[73,83]$ and has been associated with more severe disease and worse treatment outcome after endoscopic sinus surgery in comparison with non-biofilm CRS $[84,85]$.

\section{Modelling the URT microenvironment and microbiota}

Representative in vitro models of the upper respiratory tract and its microbiota can provide an elegant platform to conduct mechanistic research on chronic rhinosinusitis. A proper in vitro model allows the exploration of a number of fundamental hypotheses in a simplified and controlled environment and selection of the conditions subsequently to be tested in vivo. Due to the ambiguous aetiology of CRS, an optimal model should comprise, in 
close interaction, host components as well as microbial components. An overview of these techniques is presented in Fig. 2.

Requirement host interface A first constituent of the host in vitro microenvironment is the respiratory epithelium lining the deeper sinonasal cavity. It forms the primary site of interaction with the external environment and its microbiota. Incoming microbes have to cope with the innate (and adaptive) immune defences during attachment and growth. Therefore, in vitro models should include a differentiated epithelial structure with ciliated and non-ciliated, goblet and basal cells, with the following functionalities: mucus production, ciliary movement, barrier function and cytokine, chemokine and AMP secretion. Furthermore, apical-basolateral differentiation is needed for bacterial attachment. Currently, the only in vitro models expressing these traits are differentiated ALI epithelial cell cultures and organotypic explants [86].

Another point of attention is the altered physical host conditions in a CRS environment. Mechanistic research to address the question whether inflammation versus infection causes CRS requires a model in which a diseased host environment can be induced to observe the effects of inflammation or defective immune defence to the resident microbiota. A functional immune component is a second requirement of a sinonasal host-microbe interaction (HMI) model. This condition could be met by the incorporation of immune cells [87]. Ideally, the $\mathrm{T}_{H} 2$ - or $\mathrm{T}_{H} 1 / \mathrm{T}_{H} 17$-skewed immune responses in the CRS suband endotypes, as previously described [3, 4], should be comprised in the model.

Requirement microbial interface Research on hypotheses regarding the role of microorganisms in CRS aetiology and pathogenesis on the other hand requires a healthy host component reacting to an infecting pathogen or microbiota in dysbiosis. The microbial compartment of a CRS model should consist of a diverse, complex community, as observed in vivo. To sustain a representative in vitro sinonasal microbiome, a host compartment providing the correct microenvironment as well as a representative healthy or CRS inoculum is a

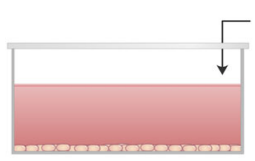

2D submerged culture

d

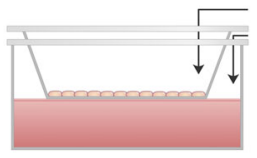

2D ALI culture

g

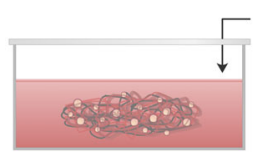

3D scaffold culture b

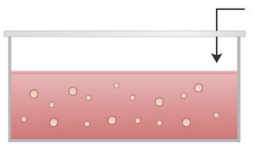

suspension culture

e

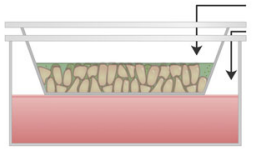

differentiated ALI culture

h

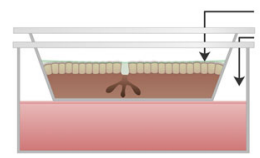

nasal or sinus tissue explant

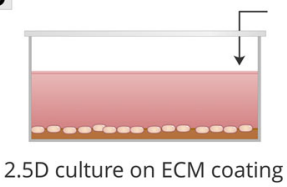

f

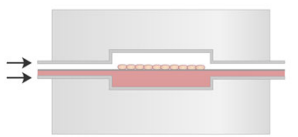

cell culture in microfluidic model

i

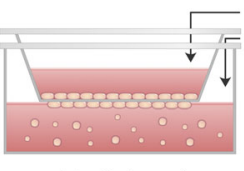

Fig. 2 Schematic overview of the categories of cell culture used to model airway tissue and host-microbe interaction in the airways. Black arrows indicate where addition of bacteria, bacterial cell wall compounds and/or other antigens is possible to mimic host-microbe interaction. a Two-dimensional (2D) submerged culture, also known as conventional monolayers. Cells are typically cultured directly on a substrate such as plastic. b Suspension culture of non-adherent cells, e.g. undifferentiated immune cells. c Two and one-half-dimensional (2.5D) culture. Cells are cultured on top of a layer of ECM. $\mathbf{d} 2 \mathrm{D}$ culture at air-liquid interface (ALI). During ALI conditions, cells cultured on porous (membrane) inserts are deprived of medium in the apical compartment, exposing them to the atmosphere and requiring them to take up nutrients from the basolateral compartment. e Differentiated ALI culture. Histologically realistic epithelial tissues can be constructed in stages, with initial assembly of airway epithelial cells into an epithelial cell layer (2D monolayer) on a submerged culture insert, followed by exposure of these cells to an air-liquid interface during a period of 2-4 weeks to induce the formation of polarised, pseudostratified airway epithelium with basal cells, ciliated cells and mucin-secreting goblet cells. $\mathbf{f}$ Cell culture in microfluidic model. ALI culture in a microfluidic model is an approach that mimics the in vivo environment more closely than static cell culture models. $\mathbf{g} 3 \mathrm{D}$ scaffold culture. Cells are cultured in and/or on biomimetic scaffolds, submerged or at ALI. $\mathbf{h}$ Nasal or sinus tissue explants. Excised nose or sinus epithelium from patients or healthy controls is cultured on a tissue culture insert that is either submerged in medium or maintained at an air-liquid interface. i Multicellular models. The combination of different cell types within a model is a strategy to more accurately represent the host microenvironment and the interactions therein. Airway epithelial cells can be combined with endothelial or immune cells to mimic host-microbe interaction on different levels 
needed. As elaborated above, it is still not clear whether a CRS microbiota composition, distinctive from a healthy sinonasal microbiota, exists; therefore, it might be of more interest to investigate the functional differences between healthy and CRS communities.

In vitro CRS models are still at an early developmental phase. Existing models are limited to either host-only models, represented by ex vivo tissues, primary cell cultures and immortal cell lines, or microbe-only models. Microbial models for CRS lack the diverse community composition seen in the sinonasal environment but are rather focused on limited species competition or interaction assays (e.g. between Staphylococcus aureus, Streptococcus pneumoniae and Haemophilus influenzae [88] and between S. pneumoniae and H. influenzae [89]). The same restriction applies for in vitro modelling of host-microbe interactions in CRS as existing models are co-culture systems of host cells with one or two microbial species (e.g. airway epithelial cells with $S$. aureus) $[68,90]$. These models allow investigation of specific inflammatory mechanisms, competition between microbial species and particular host-microbe exchanges. However, they suffer from a reduced complexity, unable to mimic the role of the commensal microbiota in this multifactorial disease. An overview of current in vitro models for CRS is given.

\section{Mimicking the host microenvironment}

Interest in upper respiratory tract diseases has resulted in the development of multiple in vitro models to study the response of airway epithelium to allergen and antigen exposure. Models that can be used to mimic upper airway epithelium are two-dimensional monolayers (2D), differentiated pseudostratified cell layers either submerged or at air-liquid interface (ALI) (between 2D and $3 \mathrm{D})$ and $3 \mathrm{D}$ cell culture models (co-cultures, explants and 3D scaffolds). Microporous polymer membranes and conventional plates are commonly used and can be adjusted with coatings (2.5D culture), most often collagen, to mimic the natural extracellular matrix [91]. Alternatively, biomimetic (electrospun) structures [87, 92] or decellularized tissues [93] can be used as substrates for cell culture. The choice of substrate is important as it can influence cell attachment, polarity, differentiation and barrier formation [91].

Cell types Immortal cell lines commonly used to mimic the URT are 16HBE (human bronchial epithelial cells) and Calu-3 and A549 (cells from human lung carcinoma) [94-96]. Immortal cell lines have the advantages of easy acquisition, source reliability and low cost. The ability to repeat experiments and yield reproducible results is another benefit. Disadvantages of immortal cell lines are the altered geno- and phenotype compared to in vivo tissue and the inability to obtain a desired disease phenotype (e.g. CRS). Furthermore, tissue-specific material is not always available or adequate for use in particular experiments. Primary patient material, such as cells from nasal brushings and epithelial cells isolated from sinus tissue or nasal polyps, has the advantage of retaining an in vivo-like phenotype and can be both disease- and tissue-specific [54, 62, 68]. Disease-specific materials, such as nasal polyp-derived cells, model the impaired sinonasal epithelium more accurately in terms of paracellular permeability and ciliary movement [54]. Disadvantages of primary patient material are the source variability, the ethical issues with sampling, the high cost, the low reproducibility due to biological variation and the specialised laboratory personnel required. However, there has been an increase in the commercial availability of primary cells and disease-specific primary cells (e.g. American Type Culture Collection), partly overcoming these drawbacks.

Conventional monolayers or suspension cultures $2 \mathrm{D}$ monolayers in conventional plastic plates and membrane inserts are the most commonly used models for airway epithelial cell cultures. They can be optimised with coatings (e.g. collagen), sometimes referred to as $2.5 \mathrm{D}$ cell culture [91]. They are easy in use and are relatively low in labour intensity, requirement for specialised laboratory personnel, time demand and cost. Airway epithelial cell monolayers are obtained by seeding cells on a substrate or scaffold and culturing them until fully confluent. 2D monolayers of, for example, but not limited to, primary human nasal epithelial cells can be repeatedly brought to ALI to study exposure to specified atmospheric conditions. During ALI conditions, cells cultured on porous (membrane) inserts are deprived of medium in the apical compartment, exposing them to the atmosphere and requiring them to take up nutrients from the basolateral compartment. These conditions allow the cell layer to mimic in vivo functionality more closely than immortal cell lines in submerged culture [97]. Despite the obvious advantages offered by this model, it should be noted that 2D monolayers differ significantly from in vivo epithelial structures and differentiated ALI cultures. In a study by Clark et al. [98], the transcriptional profiles of a 2D monolayer and a differentiated ALI structure, both consisting of primary human tracheal epithelial cells, were compared in an unstimulated state and following stimulation with flagellin. Flagellin is the main component of flagella and is primarily recognised by and activates downstream signalling of Toll-like receptor 5 . The most important source of variation between the transcriptional profiles appeared to be the culture method (2D monolayer versus ALI culture), as opposed to flagellin stimulation. 2D monolayers displayed a more 
extensive immune response upon flagellin exposure compared to ALI cultures. The monolayer-stimulated transcriptional profile was characterised by upregulation of a wide array of genes involved in wound repair, inflammation and immunity, whereas a more modest response was observed in ALI cultures. This muted response might represent a more in vivo-like behaviour and serve as a protection against an excessive proinflammatory reaction. Research on the host response upon stimulation with bacterial material or allergens is not limited to epithelial structures but can be expanded into the immune compartment. Suspension cultures of immune cells can be used to examine immunological responses to CRS-associated allergens. Larsen et al. [99] used UV-killed commensal and pathogenic airway bacteria to examine dendritic cell maturation and pro- and anti-inflammatory immune stimulation to shed light on the role of changes in the airway microbiota in inflammatory airway diseases. Li et al. [100] used this method to study the reaction of peripheral blood monocytic cells to heat-killed S. aureus and observed downregulation of $\mathrm{T}_{H} 1$ responses, offering a possible explanation for the $\mathrm{T}_{H} 2$ inflammatory environment often observed in CRS.

Between 2D and 3D: differentiated cell layers A wellestablished model for airway epithelium research is cell culture with differentiated airway epithelium at ALI. In practice, airway epithelial cells (cell lines or primary cells) are seeded on a microporous membrane and kept under submerged conditions, with medium in both apical and basal compartments, until full confluence (2D conventional monolayer). When the monolayer has reached confluency, the medium on the apical side is removed. This leaves the apical side exposed to air, while nutrients and fluids need to be obtained from the basal compartment. Apical exposure to air results in more representative mucus production compared to submersed culture in an airway epithelial cell line (Calu-3) [96]. At this point, the monolayer can differentiate in a period of 2-4 weeks from a 2D conventional monolayer to a polarised, pseudostratified epithelial structure composed of basal cells, ciliated cells and mucin-secreting goblet cells [62]. Differentiated cell layers are the followup stage of 2D monolayers but can be distinguished from the latter by their morphology and functionality. The multi-layered epithelial structure mimics the physiological barrier function in the respiratory tract with its functional tight junctions. ALI cultures have a more representative phenotype of the in vivo epithelium and can be maintained for a longer period (weeks to months) in comparison with medium-submerged monolayers $[95,101,102]$. A fully automated model for ALI culture of primary cells, called CULTEX ${ }^{\circ}$ LTC-C (long- term cultivation continuous) has been developed by Aufderheide et al. [103]. The CULTEX LTC-C provides temperature control, semi-continuous medium supply and automated medium-level adjustment, hereby increasing the quality and reproducibility of the culturing process, while reducing the labour intensity of conventional cell culture. Other non-automated differentiated ALI models of the upper respiratory tract are commercially available. The MucilAir ${ }^{\text {rm }}$-HF model consists of primary nasal cells co-cultured with human fibroblasts, and the EpiAirway ${ }^{\mathrm{Tm}}$ model contains primary human tracheal/ bronchial cells and also exists as a co-culture with fibroblasts. Blume et al. [94] developed a dynamic microfluidic model of differentiated primary airway epithelial cells at ALI that allows close monitoring of immune responses of the cell layer. These different airway epithelial models allow research on exposure to environmental allergens [94, 104-106] and could be optimised for disease-specific purposes. Epithelial response to the presence of bacteria can be simulated by exposure to bacterial cell wall components such as lipopolysaccharide (LPS), flagellin or bacterial toxins such as $S$. aureus enterotoxin B and $S$. aureus alpha toxin, upon which innate immune responses of CRS-derived cultures can be compared to those originating from healthy controls $[54,69,98]$.

Multicellular models and 3D scaffolds The combination of different cell types within a model is a strategy to more accurately represent the host microenvironment and the interactions therein. Benam et al. [107] developed an ALI lung-on-chip model of human bronchioles with epithelial and endothelial tissue to investigate inflammatory reactions in chronic obstructive pulmonary disease and asthma. This model comprised an endothelial cell layer with primary cells to mimic the expression of receptors required for neutrophil rolling (transient adhesion to E-selectin) and more firm adhesion (to ICAM1 ), as observed during in vivo inflammation. Recently, an immunocompetent 3D model at ALI of the upper respiratory tract was developed [87]. The tri-culture model consisted of three biomimetic electrospun scaffolds upon which, from bottom to top, respectively fibroblasts (MRC-5 cell line), dendritic cells (isolated from peripheral blood lymphocytes) and differentiated epithelial cells (Calu-3 cell line) were grown. As a proof of concept of immune response, dendritic cells were shown to migrate through the scaffolds and cell layers upon allergen exposure.

\section{Host-microbe co-culture models}

Host-microbe co-culture models offer the possibility to investigate host-microbe interaction in a controlled environment with reduced complexity compared to human 
and animal models. This facilitates control of specific conditions and exploration of novel therapeutic strategies. The improved technical ability to create in vitro differentiated host models and the combination with multiple omics techniques allows improved insight in host-microbe crosstalk during infection and (inflammatory) responses [35, 68, 108]. Current co-culture models of the respiratory tract have mainly focused on colonisation with a single pathogenic $[68,90,108,109]$ or probiotic species [110]. The models can be used to monitor short-term host-microbe interactions, such as innate immune responses of the epithelial cells and physiological changes of bacterial and epithelial cells such as cytokine production and tight junction functionality [68, 90]. Starner et al. [109] developed the first in vitro model for bacterial biofilm formation on polarised human airway epithelia. Differentiated Calu-3 epithelial cells at ALI were used in co-culture with $H$. influenzae for four consecutive days, during which the epithelial cells remained viable. The model allowed follow-up of innate immune responses and biofilm formation. A similar set-up was used to study $S$. aureus colonisation of airway epithelial cells and the physiological changes that occurred during the colonisation process [90]. However, the epithelial layer was completely disrupted within 1 day after inoculation of wild-type S. aureus. Baddal et al. [108] have used simultaneous whole genome transcriptional profiling of host cells and a $H$. influenzae strain invading primary differentiated airway epithelium. Pathogenmediated signalling pathways and significant dysregulation of the target cytoskeletal network upon intracellular infection were identified. This approach also enabled discovery of host adaptation pathways in the pathogen and metabolic signature traits of nasopharyngeal colonisation. Another co-culture model to study early innate immune responses of airway epithelium upon bacterial infection was developed by Kohanski and Lane [68]. The host environment was mimicked by an ALI-differentiated structure of sinonasal epithelial cells from CRS patients with and without nasal polyps and non-CRS controls. Distinguished inflammatory responses could be observed for the CRS subtypes upon infection with S. aureus, suggesting that the primary material has an inflammatory memory and could therefore be used to mimic the host environment more adequately. A submerged monolayer of human bronchial epithelium cells (HBE014 cell line) was used to investigate phenotype switching to small colony variants of $S$. aureus upon internalisation in epithelial cells and the subsequent effect on the immune response [111]. It was shown that intracellular S. aureus did not elicit excretion of the pro-inflammatory IL-6, contrarily to extracellular S. aureus. Cytotoxic effects were neither induced. A similar approach was followed to examine the differences between wild type and small colony producing
S. aureus in epithelial cell invasion and subsequent host immune response [112]. Small colony variant producing $S$. aureus was shown to elicit a less widespread innate immune response at similar colonisation rates, thus evading clearance by the host. These findings could help explain bacterial persistence in CRS [111, 112].

Existing models are limited in the time frame of the host-microbe co-culture and the ability to adequately mimic the URT microenvironment; due to cell toxicity, the duration of host-live microbe co-cultures with direct contact between mammalian cells and bacteria is currently limited to hours or days $[68,90,108]$. This duration can be used for investigation of initial attachment and colonisation of bacteria but does not permit examination of bacterial persistence strategies. Starner et al. [109] inoculated $H$. influenzae with a multiplicity of infection of 20 bacteria/host cell and retained viable epithelial cells until 4 days post-inoculation. Remarkably, Ren et al. $[113,114]$ have used the EpiAirway ${ }^{\text {tm }}$ model for co-culture of the host compartment with $H$. influenzae, extending the co-culture period to 10 days. Key aspects for success were the low multiplicity of infection (0.0110 bacteria/host cell) and daily washes with phosphatebuffered saline. Another limitation to current models is failure of the host compartment to adequately mimic the host microenvironment as most often undifferentiated host cell monolayers or differentiated epithelial cell cultures are used, without taking into account tissuespecific mechanical or chemical stimuli. Organ-on-chip models offer a way to take these stimuli into account mimicking the spatial structures and mechanical stimuli observed in host tissue in microfluidic devices [107, 115, 116]. The ALI culture method, also applied in these devices, provides conditions for co-culture resembling the in vivo situation, where bacteria are exposed to atmospheric conditions and are obliged to acquire nutrients and growth factors through the epithelial cell layer.

\section{Microbial co-culture models}

The majority of in vitro studies on URT infections have focused on competition assays between two microbial species. However, model systems for the URT microbiota in health and CRS are required to gain mechanistic insight in the factors that influence microbial colonisation behaviour, growth characteristics and community composition and the impact thereof on the expression of pathogenic traits and disease aetiology and evolution.

Mucostasis, a result of reduced ciliary movement and ostium obstruction, is commonly observed in the paranasal sinuses of CRS patients and can result in the accumulation of microorganisms and other immunogenic compounds in the paranasal sinuses. Furthermore, it alters the spatial structure of the growth surface of the bacterial community, a parameter known to impact colonisation behaviour [117]. 
The altered, inflammatory microenvironment can influence the community composition, as some species are more susceptible to host defence mechanisms than others. Microbial co-culture models can range from two-species co-cultivation over synthetic communities to natural communities. Simple co-cultivation models offer the advantage of a low complexity, high controllability and relative ease to analyse, but often lack representative in vivo behaviour. Natural communities typically display a higher level of complexity and have a broader and more representative functionality. Disadvantages are the lower controllability and reproducibility and difficulty of analysis. Synthetic communities combine the advantages of both systems by having a broader functionality than simple cocultures, while being more controllable and reproducible than complex communities [118]. Recent research on healthy and CRS sinonasal microbiota indicates the existence of community state types [119] or disease subgroups [9] with distinctive bacterial compositions. This offers the opportunity to develop different synthetic communities associated with CRS phenotypes and opens the way to precision research and medicine.

Competition assays between two microbial species enable the investigation of specific interaction between these species in a relatively simple set-up and may lead to discovery of novel strategies to prevent pathogenic infections. Biofilm co-culture experiments are especially relevant in CRS research and have for example been used to study species interactions before and during the biofilm state. In vitro studies demonstrated that Staphylococcus epidermidis can have an inhibitory effect on S. aureus biofilm formation [120, 121], partly explaining the negative correlation between $S$. epidermidis colonisation and $S$. aureus carriage observed in hospitalised patients [122]. S. aureus and $H$. influenzae are regularly observed together in CRS-associated biofilms [85]. The interactions between $S$. pneumoniae and $H$. influenzae were investigated during pre-biofilm planktonic growth and biofilm formation, and the inclination towards antagonism or mutualism was shown to be largely dependent on environmental parameters such as growth phase and nutrient availability [123]. Interspecies interactions in $S$. aureus biofilm formation and coaggregation were examined between nostril-dwelling $S$. aureus and Propionibacterium spp., where a porphyrin compound excreted by Propionibacterium spp. was found to induce $S$. aureus aggregation and biofilm formation [124]. More simplistic co-culture models include agar competition experiments and broth co-culture. Cope et al. [89] demonstrated interspecies interactions and their influence on virulence gene expression between $H$. influenzae and S. pneumoniae both in vitro and ex vivo in human CRS sinus tissue. $H$. influenzae type IV pili, important for epithelial colonisation and biofilm formation, were only expressed in co-culture in vitro, whereas $S$. pneumoniae virulence factors associated with acute infection and epithelial damage were downregulated, adhering to a more chronic infection model. Yan et al. [25] first studied bacterial community differences between persistent and non-persistent $S$. aureus carriers and found a co-occurrence between $S$. aureus and Corynebacterium accolens, while Corynebacterium pseudodiphteriticum was observed more often in nonpersistent carriers. Growth interaction assays on agar plates revealed that $S$. aureus and C. accolens supported each others' growth, while C. pseudodiphteriticum growth was less supported by $S$. aureus and C. pseudodiphteriticum even inhibited S. aureus [25].

CRS is a multifactorial disease, as elaborated previously, and despite the established importance of $S$. aureus and other pathogenic species in the disease, it is unlikely to be caused by a single infectious microorganism. It is rather to be expected that, on the bacterial side, an imbalance in the microbial community plays a role. The reductionist approach of two or multiple species cocultures is unable to answer research questions on colonisation and growth dynamics in the complex, precolonised mucosal environment seen in CRS. Considering CRS as a poly-microbial disease, research on complex communities, deciphering co-occurrence patterns, mutualistic interactions and the importance of the relative abundance of the community members, is indispensable to understand CRS and find appropriate treatment or preventive strategies [125]. Reduced community evenness has been shown to decrease resistance to invasion [126], which could facilitate pathogen colonisation in CRS community in state of dysbiosis and further CRS pathogenesis. It is in this ecosystemic framework that further CRS research initiatives should take place.

Bacterial co- or mixed culture experiments have the major disadvantage of omitting the host's immune responses and thus omitting within-host competition behaviour [127] and more broadly the effects of microbial co-infection [128, 129]. Within-host competition is a strategy during which a species elicits an immune response to which it is resistant itself, but that is able to clear the niche of competing organisms. These off-target immune defences comprise cross-reacting antibodies, recruitment of polymorphonuclear cells and production of antimicrobial proteins. Immunological effects can severely influence and even revert competition outcomes compared to in vitro observations [127].

\section{Conclusion}

Chronic rhinosinusitis is a multifactorial disease of uncertain aetiology, driven by host immune responses, microbial dysbiosis and exposure to environmental irritants. 
Mechanistic research to unravel aetiopathologic pathways of this disease and find innovative prophylactic or treatment approaches requires in vitro models of the affected tissues and their resident microbiota. Current models are either limited to host cells, competition assays between few airway species or simple host-pathogen co-cultures. To adequately mimic host and microbial behaviour in CRS, a less reductionist approach is needed, in particular on the microbial aspect. A polymicrobial, dynamic community is a prerequisite to investigate pathogen colonisation and inflammatory responses elicited in the host. Long-term models are needed to analyse shifts in the microbial community composition and functionality during CRS and how these communities can be modulated to improve chronic inflammation and restore host-microbe balance in the sinonasal cavities.

\section{Abbreviations}

ALI: Air-liquid interface; AMP: Antimicrobial protein; ASL: Airway surface liquid; CRS: Chronic rhinosinusitis; CRSsNP: Chronic rhinosinusitis without nasal polyps; CRSwNP: Chronic rhinosinusitis with nasal polyps; IFN: Interferon; Ig: Immunoglobulin; IL: Interleukin; LPS: Lipopolysaccharide; NP: Nasal polyps; PLUNC: Palate, lung, nasal epithelial clone; SPLUNC-1: Short palate, lung, nasal epithelial clone 1; T2R: Type 2 receptor; URT: Upper respiratory tract

\section{Acknowledgements}

The authors want to thank Tim Lacoere for the excellent graphical work. The kind help of Ilke De Boeck for proofreading the manuscript is acknowledged as well.

\section{Funding}

CDR and SL were supported by an SBO grant (ProCure: project no. 150052) and MCA benefitted from an FWO postdoctoral fellowship Research Foundation - Flanders (118499/12R2717N LV).

\section{Authors' contributions}

CDR, MCA, TVdW and SL wrote the manuscript. All authors read and approved the manuscript.

\section{Ethics approval and consent to participate}

Not applicable.

\section{Competing interests}

The authors declare that they have no competing interests.

\section{Publisher's Note}

Springer Nature remains neutral with regard to jurisdictional claims in published maps and institutional affiliations.

\footnotetext{
Author details

${ }^{1}$ Center for Microbial Ecology and Technology, Faculty of Bioscience Engineering, Ghent University, Coupure Links 653, B-9000 Ghent, Belgium. ${ }^{2}$ Research Group of Environmental Ecology and Applied Microbiology, Department of Bioscience Engineering, University of Antwerp, Groenenborgerlaan 171, 2020 Antwerp, Belgium.
}

Received: 17 November 2017 Accepted: 17 April 2018 Published online: 24 April 2018

\section{References}

1. Hastan D, Fokkens WJ, Bachert C, Newson RB, Bislimovska J, Bockelbrink A, Bousquet PJ, Brozek G, Bruno A, Dahlen SE, Forsberg B, Gunnbjornsdottir M, Kasper L, Kramer U, Kowalski ML, Lange B, Lundback B, Salagean E, TodoBom A, Tomassen P, Toskala E, van Drunen CM, Bousquet J, Zuberbier
T, Jarvis D, Burney P. Chronic rhinosinusitis in Europe-an underestimated disease. A Ga(2)len study. Allergy. 2011;66(9):1216-23.

2. Fokkens WJ, Lund VJ, Mullol J, Bachert C, Alobid I, Baroody F, Cohen N, Cervin A, Douglas R, Gevaert P, Georgalas C, Goossens H, Harvey R, Hellings P, Hopkins C, Jones N, Joos G, Kalogjera L, Kern B, Kowalski M, Price D, Riechelmann H, Schlosser R, Senior B, Thomas M, Toskala E, Voegels R, Wang DY, Wormald PJ. Epos 2012: European position paper on rhinosinusitis and nasal polyps 2012. A summary for otorhinolaryngologists. Rhinology. 2012;50(1):1-12.

3. Akdis CA, Bachert C, Cingi C, Dykewicz MS, Hellings PW, Naclerio RM, Schleimer RP, Ledford D. Endotypes and phenotypes of chronic rhinosinusitis: a PRACTALL document of the European Academy of Allergy and Clinical immunology and the American Academy of Allergy, Asthma \& Immunology. J Allergy Clin Immunol. 2013;131(6):1479-90.

4. Tomassen P, Vandeplas G, Van Zele T, Cardell LO, Arebro J, Olze H, ForsterRuhrmann U, Kowalski ML, Olszewska-Ziaber A, Holtappels G, De Ruyck N, Wang XD, Van Drunen C, Mullol J, Hellings P, Hox V, Toskala E, Scadding G, Lund V, Zhang L, Fokkens W, Bachert C. Inflammatory endotypes of chronic rhinosinusitis based on cluster analysis of biomarkers. J Allergy Clin Immunol. 2016;137(5):1449.

5. Lam K, Schleimer R, Kern RC. The etiology and pathogenesis of chronic rhinosinusitis: a review of current hypotheses. Curr Allergy Asthma Rep. 2015:15(7):1-10.

6. Aurora R, Chatterjee D, Hentzleman J, Prasad G, Sindwani R, Sanford T. Contrasting the microbiomes from healthy volunteers and patients with chronic rhinosinusitis. JAMA Otolaryngol Head Neck Surg. 2013;139(12): 1328-38.

7. Choi EB, Hong SW, Kim DK, Jeon SG, Kim KR, Cho SH, Gho YS, Jee YK, Kim YK. Decreased diversity of nasal microbiota and their secreted extracellular vesicles in patients with chronic rhinosinusitis based on a metagenomic analysis. Allergy. 2014;69(4):517-26.

8. Cope EK, Lynch SV. Novel microbiome-based therapeutics for chronic rhinosinusitis. Curr Allergy Asthma Rep. 2015;15(3):1-10.

9. Cope EK, Goldberg AN, Pletcher SD, Lynch SV. Compositionally and functionally distinct sinus microbiota in chronic rhinosinusitis patients have immunological and clinically divergent consequences. Microbiome. 2017:5:1-16.

10. Mackenzie BW, Waite DW, Hoggard M, Douglas RG, Taylor MW, Biswas K. Bacterial community collapse: a meta-analysis of the sinonasal microbiota in chronic rhinosinusitis. Environ Microbiol. 2017;19(1):381-92.

11. Abreu NA, Nagalingam NA, Song YL, Roediger FC, Pletcher SD, Goldberg AN, Lynch SV. Sinus microbiome diversity depletion and Corynebacterium tuberculostearicum enrichment mediates rhinosinusitis. Sci Transl Med. 2012; 4(151):1-19.

12. Weyrich LS, Feaga HA, Park J, Muse SJ, Safi CY, Rolin OY, Young SE, Harvill ET. Resident microbiota affect Bordetella pertussis infectious dose and host specificity. J Infect Dis. 2014;209(6):913-21.

13. Man WH, Piters WAAD, Bogaert D. The microbiota of the respiratory tract: gatekeeper to respiratory health. Nat Rev Microbiol. 2017;15(5):259-70.

14. Khosravi A, Yanez A, Price JG, Chow A, Merad M, Goodridge HS, Mazmanian SK. Gut microbiota promote hematopoiesis to control bacterial infection. Cell Host Microbe. 2014;15(3):374-81.

15. Piters WAAD, Sanders EAM, Bogaert D. The role of the local microbial ecosystem in respiratory health and disease. Philos Trans R Soc B Biol Sci. 2015:370(1675).

16. Wilson MT, Hamilos DL. The nasal and sinus microbiome in health and disease. Curr Allergy Asthma Rep. 2014;14(12):1-10.

17. Allen EK, Koeppel AF, Hendley JO, Turner SD, Winther B, Sale MM. Characterization of the nasopharyngeal microbiota in health and during rhinovirus challenge. Microbiome. 2014;2:1-11.

18. Bassiouni A, Cleland EJ, Psaltis AJ, Vreugde S, Wormald PJ. Sinonasal microbiome sampling: a comparison of techniques. PLoS One. 2015;10(4):1-13.

19. Bassis CM, Tang AL, Young VB, Pynnonen MA. The nasal cavity microbiota of healthy adults. Microbiome. 2014;2:1-5.

20. Biswas K, Hoggard M, Jain R, Taylor MW, Douglas RG. The nasal microbiota in health and disease: variation within and between subjects. Front Microbiol. 2015;6:1-9.

21. Camarinha-Silva A, Jauregui R, Chaves-Moreno D, Oxley APA, Schaumburg F, Becker K, Wos-Oxley ML, Pieper DH. Comparing the anterior nare bacterial community of two discrete human populations using Illumina amplicon sequencing. Environ Microbiol. 2014;16(9):2939-52. 
22. Feazel LM, Robertson CE, Ramakrishnan VR, Frank DN. Microbiome complexity and Staphylococcus aureus in chronic rhinosinusitis. Laryngoscope. 2012;122(2):467-72.

23. Joss TV, Burke CM, Hudson BJ, Darling AE, Forer M, Alber DG, Charles IG, Stow NW. Bacterial communities vary between sinuses in chronic rhinosinusitis patients. Front Microbiol. 2016;6:1-11.

24. Ramakrishnan VR, Feazel LM, Gitomer SA, Ir D, Robertson CE, Frank DN. The microbiome of the middle meatus in healthy adults. PLoS One. 2013;8(12):1-10.

25. Yan ML, Pamp SJ, Fukuyama J, Hwang PH, Cho DY, Holmes S, Relman DA. Nasal microenvironments and interspecific interactions influence nasal microbiota complexity and S. aureus carriage. Cell Host Microbe. 2013;14(6):631-40

26. Shin HW. Animal models in CRS and pathophysiologic insights gained: a systematic review. Laryngoscope Investig Otolaryngol. 2016;1(5):116-23.

27. Jardeleza C, Thierry B, Rao S, Rajiv S, Drilling A, Miljkovic D, Paramasivan S, James C, Dong D, Thomas N, Vreugde S, Prestidge CA, Wormald PJ. An in vivo safety and efficacy demonstration of a topical liposomal nitric oxide donor treatment for Staphylococcus aureus biofilm-associated rhinosinusitis. Transl Res. 2015;166(6):683-92.

28. Shin HW, Kim DK, Park MH, Eun KM, Lee M, So D, Kong IG, PhD JHMM, Yang MS, Jin HR, Park JW, Kim DW. IL-25 as a novel therapeutic target in nasal polyps of patients with chronic rhinosinusitis. J Allergy Clin Immunol. 2015;135(6):1476-U135

29. Kim SW, Kim JH, Jung MH, Hur DG, Lee HK, Jeon SY, Kim DW. Periostin may play a protective role in the development of eosinophilic chronic rhinosinusitis with nasal polyps in a mouse model. Laryngoscope. 2013; 123(5):1075-81.

30. Cope EK, Goldberg AN, Pletcher SD, Lynch SV. A chronic rhinosinusitisderived isolate of Pseudomonas aeruginosa induces acute and pervasive effects on the murine upper airway microbiome and host immune response. Int Forum of Allergy Rhinol. 2016;6(12):1229-37.

31. Crabbe A, Ledesma MA, Nickerson CA. Mimicking the host and its microenvironment in vitro for studying mucosal infections by Pseudomonas aeruginosa. Pathog Dis. 2014;71(1):1-19.

32. Marzorati M, Vanhoecke $B$, De Ryck T, Sadabad MS, Pinheiro I, Possemiers $S$, Van den Abbeele P, Derycke L, Bracke M, Pieters J, Hennebel T, Harmsen HJ, Verstraete W, Van de Wiele T. The HMI ${ }^{\mathrm{TM}}$ module: a new tool to study the host-microbiota interaction in the human gastrointestinal tract in vitro. BMC Microbiol. 2014;14:1-14.

33. Shah P, Fritz JV, Glaab E, Desai MS, Greenhalgh K, Frachet A, Niegowska M, Estes M, Jager C, Seguin-Devaux C, Zenhausern F, Wilmes P. A microfluidicsbased in vitro model of the gastrointestinal human-microbe interface. Nat Commun. 2016;7:1-15.

34. Van den Abbeele P, Roos S, Eeckhaut V, Mackenzie DA, Derde M, Verstraete W, Marzorati M, Possemiers S, Vanhoecke B, Van Immerseel F, Van de Wiele T. Incorporating a mucosal environment in a dynamic gut model results in a more representative colonization by lactobacilli. Microb Biotechnol. 2012;5(1):106-15.

35. De Ryck T, Grootaert C, Jaspaert L, Kerckhof FM, Van Gele M, De Schrijver J, Van den Abbeele P, Swift S, Bracke M, Van de Wiele T, Vanhoecke B. Development of an oral mucosa model to study host-microbiome interactions during wound healing. Appl Microbiol Biotechnol. 2014; 98(15):6831-46.

36. Hamilos DL. Host-microbial interactions in patients with chronic rhinosinusitis. J Allergy Clin Immunol. 2014;133(3):640.

37. Hamilos DL. Drivers of chronic rhinosinusitis: inflammation versus infection J Allergy Clin Immunol. 2015;136(6):1454-9.

38. Scheckenbach K, Wagenmann M. Cytokine patterns and endotypes in acute and chronic rhinosinusitis. Curr Allergy Asthma Rep. 2016;16(1):1-8.

39. Stevens WW, Lee RJ, Schleimer RP, Cohen NA. Chronic rhinosinusitis pathogenesis. J Allergy Clin Immunol. 2015;136(6):1442-53.

40. Mahdavinia M, Keshavarzian A, Tobin MC, Landay AL, Schleimer RP. A comprehensive review of the nasal microbiome in chronic rhinosinusitis (CRS). Clin Exp Allergy. 2016;46(1):21-41

41. Hoggard M, Biswas K, Zoing M, Mackenzie BW, Taylor MW, Douglas RG. Evidence of microbiota dysbiosis in chronic rhinosinusitis. Int Forum Allergy Rhinol. 2017:7(3):230-9.

42. F. Paulsen and J. Waschke. Sobotta-Atlas of Human Anatomy: Head, Neck and Neuroanatomy, volume 3, chapter nose. $15^{\text {th }}$ edition, 58-61. Elsevier Gmbh, Munich. 2011.
43. Elad D, Wolf M, Keck T. Air-conditioning in the human nasal cavity. Respir Physiol Neurobiol. 2008;163(1-3):121-7.

44. Nizet $\mathrm{V}$, Johnson RS. Interdependence of hypoxic and innate immune responses. Nat Rev Immunol. 2009;9(9):609-17.

45. Ding GQ, Zheng CQ. The expression of muc5ac and muc5b mucin genes in the mucosa of chronic rhinosinusitis and nasal polyposis. Am J Rhinol. 2007; 21(3):359-66.

46. Jiao J, Duan S, Meng N, Li Y, Fan E, Zhang L. Role of IFN-Y, IL-13, and IL-17 on mucociliary differentiation of nasal epithelial cells in chronic rhinosinusitis with nasal polyps. Clin Exp Allergy. 2016;46(3):449-60.

47. Kim YJ, Cho HJ, Shin WC, Song HA, Yoon JH, Kim CH. Hypoxia-mediated mechanism of MUC5AC production in human nasal epithelia and its implication in rhinosinusitis. PLoS One. 2014;9(5):1-10.

48. Saieg A, Brown KJ, Pena MT, Rose MC, Preciado D. Proteomic analysis of pediatric sinonasal secretions shows increased MUC5B mucin in CRS. Pediatr Res. 2015;77(2):356-62.

49. Leung RM, Kern RC, Conley DB, Tan BK, Chandra RK. Osteomeatal complex obstruction is not associated with adjacent sinus disease in chronic rhinosinusitis with polyps. Am J Rhinol Allergy. 2011;25(6):401-3.

50. Steinke JW, Woodard CR, Borish L. Role of hypoxia in inflammatory upper airway disease. Curr Opin Allergy Clin Immunol. 2008:8(1):16-20.

51. Pahlman LI, Jogi A, Gram M, Mori M, Egesten A. Hypoxia down-regulates expression of secretory leukocyte protease inhibitor in bronchial epithelial cells via TGF-beta 1. BMC Pulm Med. 2015;15:1-7.

52. Ramakrishnan VR, Gitomer S, Kofonow JM, Robertson CE, Frank DN. Investigation of sinonasal microbiome spatial organization in chronic rhinosinusitis. Int Forum Allergy Rhinol. 2017;7(1):16-23.

53. Hoenderdos K, Lodge KM, Hirst RA, Chen C, Palazzo SGC, Emerenciana A, Summers C, Angyal A, Porter L, Juss JK, O'Callaghan C, Chilvers ER, Condliffe AM. Hypoxia upregulates neutrophil degranulation and potential for tissue injury. Thorax. 2016;71(11):1030-8.

54. Bleier BS, Mulligan RM, Schlosser RJ. Primary human sinonasal epithelial cell culture model for topical drug delivery in patients with chronic rhinosinusitis with nasal polyposis. J Pharm Pharmacol. 2012;64(3):449-56.

55. Soyka MB, Wawrzyniak P, Eiwegger T, Holzmann D, Treis A, Wanke K, Kast JI, Akdis CA. Defective epithelial barrier in chronic rhinosinusitis: the regulation of tight junctions by IFN-gamma and IL-4. J Allergy Clin Immunol. 2012; 130(5):1087.

56. Ramezanpour M, Moraitis S, Smith JLP, Wormald PJ, Vreugde S. Th17 cytokines disrupt the airway mucosal barrier in chronic rhinosinusitis. Mediat Inflamm. 2016;2016:1-7.

57. Hatten KM, Palmer JN, Lee RJ, Adappa ND, Kennedy DW, Cohen NA. Corticosteroid use does not alter nasal mucus glucose in chronic rhinosinusitis. Otolaryngol Head Neck Surg. 2015;152(6):1140-4.

58. Pezzulo AA, Gutierrez J, Duschner KS, McConnell KS, Taft PJ, Ernst SE, Yahr $\mathrm{TL}$, Rahmouni K, Klesney-Tait J, Stoltz DA, Zabner J. Glucose depletion in the airway surface liquid is essential for sterility of the airways. PLoS One. 2011; $6(1): 1-8$

59. Lee RJ, Xiong GX, Kofonow JM, Chen B, Lysenko A, Jiang PH, Abraham V, Doghramji L, Adappa ND, Palmer JN, Kennedy DW, Beauchamp GK, Doulias PT, Ischiropoulos H, Kreindler JL, Reed DR, Cohen NA. T2R38 taste receptor polymorphisms underlie susceptibility to upper respiratory infection. J Clin Investig. 2012;122(11):4145-59.

60. Lee RJ, Cohen NA. Role of the bitter taste receptor T2R38 in upper respiratory infection and chronic rhinosinusitis. Curr Opin Allergy Clin Immunol. 2015;15(1):14-20.

61. Cohen NA. The genetics of the bitter taste receptor T2R38 in upper airway innate immunity and implications for chronic rhinosinusitis. Laryngoscope. 2017;127(1):44-51.

62. Yan CH, Hahn S, McMahon D, Bonislawski D, Kennedy DW, Adappa ND, Palmer JN, Jiang PH, Lee RJ, Cohen NA. Nitric oxide production is stimulated by bitter taste receptors ubiquitously expressed in the sinonasal cavity. Am J Rhinol Allergy. 2017;31(2):85-92.

63. Ooi EH, Wormald PJ, Tan LW. Innate immunity in the paranasal sinuses: a review of nasal host defenses. Am J Rhinol. 2008;22(1):13-9.

64. Tsou YA, Chen CM, Lin TC, Hu FW, Tai CJ, Chen HC, Yeh TH, Harn HJ, Tsai $\mathrm{MH}$, Jan Cl. Decreased splunc1 expression is associated with Pseudomonas infection in surgically treated chronic rhinosinusitis patients who may require repeated sinus surgery. Laryngoscope. 2013;123(4):845-51.

65. Seshadri S, Lin DC, Rosati M, Carter RG, Norton JE, Suh L, Kato A, Chandra RK, Harris KE, Chu HW, Peters AT, Tan BK, Conley DB, Grammer LC, Kern RC, 
Schleimer RP. Reduced expression of antimicrobial PLUNC proteins in nasal polyp tissues of patients with chronic rhinosinusitis. Allergy. 2012;67(7):920-8.

66. Wei Y, Han MM, Wen WP, Li HB. Differential short palate, lung, and nasal epithelial clone 1 suppression in eosinophilic and non-eosinophilic chronic rhinosinusitis with nasal polyps: implications for pathogenesis and treatment. Curr Opin Allergy Clin Immunol. 2016;16(1):31-8.

67. Yeh TH, Lee SY, Hsu WC. Expression of SPLUNC1 protein in nasal polyp epithelial cells in air-liquid interface culture treated with IL-13. Am J Rhinol Allergy. 2010;24(1):17-20.

68. Kohanski MA, Lane AP. Sinonasal epithelial cell response to Staphylococcus aureus burden in chronic rhinosinusitis. JAMA Otolaryngol Head Neck Surg. 2015;141(4):341-9.

69. Okano M, Fujiwara T, Kariya S, Higaki T, Haruna T, Matsushita O, Noda Y, Makihara S, Kanai K, Noyama Y, Taniguchi M, Nishizaki K. Cellular responses to Staphylococcus aureus alpha-toxin in chronic rhinosinusitis with nasal polyps. Allergol Int. 2014;63(4):563-73.

70. Foreman A, Holtappels G, Psaltis AJ, Jervis-Bardy J, Field J, Wormald PJ, Bachert C. Adaptive immune responses in Staphylococcus aureus biofilmassociated chronic rhinosinusitis. Allergy. 2011;66(11):1449-56.

71. Stevens WW, Ocampo CJ, Berdnikovs S, Sakashita M, Mandavinia M, Suh L, Takabayashi T, Norton JE, Hulse KE, Conley DB, Chandra RK, Tan BK, Peters AT, Grammer LC, Kato A, Harris KE, Carter RG, Fujieda S, Kern RC, Schleimer RP. Cytokines in chronic rhinosinusitis role in eosinophilia and aspirin-exacerbated respiratory disease. Am J Respir Crit Care Med. 2015;192(6):682-94.

72. Chalermwatanachai T, Zhang N, Holtappels G, Bachert C. Association of mucosal organisms with patterns of inflammation in chronic rhinosinusitis. PLoS One. 2015;10(8)1-11.

73. Boase S, Foreman A, Cleland E, Tan L, Melton-Kreft R, Pant H, Hu FZ, Ehrlich GD, Wormald PJ. The microbiome of chronic rhinosinusitis: culture, molecular diagnostics and biofilm detection. BMC Infect Dis. 2013;13:1-9.

74. Krismer B, Liebeke M, Janek D, Nega M, Rautenberg M, Hornig G, Unger C Weidenmaier C, Lalk M, Peschel A. Nutrient limitation governs Staphylococcus aureus metabolism and niche adaptation in the human nose. PLoS Pathog. 2014;10(1)1-17.

75. Bassis CM, Erb-Downward JR, Dickson RP, Freeman CM, Schmidt TM, Young VB, Beck JM, Curtis JL, Huffnagle GB. Analysis of the upper respiratory tract microbiotas as the source of the lung and gastric microbiotas in healthy individuals. MBio. 2015;6(2):1-10.

76. Chalermwatanachai T, Velasquez LC, Bachert C. The microbiome of the upper airways: focus on chronic rhinosinusitis. World Allergy Organ J. 2015;8:1-14.

77. Ramakrishnan VR, Hauser LJ, Feazel LM, Ir D, Robertson CE, Frank DN. Sinus microbiota varies among chronic rhinosinusitis phenotypes and predicts surgical outcome. J Allergy Clin Immunol. 2015;136(2):334.

78. Hauser LJ, Ir D, Kingdom TT, Robertson CE, Frank DN, Ramakrishnan VR. Investigation of bacterial repopulation after sinus surgery and perioperative antibiotics. Int Forum Allergy Rhinol. 2016;6(1):34-40.

79. Liu CM, Kohanski MA, Mendiola M, Soldanova K, Dwan MG, Lester R, Nordstrom L, Price LB, Lane AP. Impact of saline irrigation and topical corticosteroids on the postsurgical sinonasal microbiota. Int Forum Allergy Rhinol. 2015;5(3):185-90.

80. Ceri H, Olson ME, Stremick C, Read RR, Morck D, Buret A. The Calgary Biofilm Device: new technology for rapid determination of antibiotic susceptibilities of bacterial biofilms. J Clin Microbiol. 1999;37(6):1771-6.

81. Ha KR, Psaltis AJ, Butcher AR, Wormald PJ, Tan LW. In vitro activity of mupirocin on clinical isolates of staphylococcus aureus and its potential implications in chronic rhinosinusitis. Laryngoscope. 2008;118(3):535-40.

82. Tajudeen BA, Schwartz JS, Palmer JN. Understanding biofilms in chronic sinusitis. Curr Allergy Asthma Rep. 2016;16(2):1-6.

83. Glowacki R, Tomaszewski KA, Strek P, Tomaszewska IM, Zgorska-Swierzy K, Markiewicz B, Skladzien J. The influence of bacterial biofilm on the clinical outcome of chronic rhinosinusitis: a prospective, double-blind, scanning electron microscopy study. Eur Arch Otorhinolaryngol. 2014;271(5):1015-21.

84. Singhal D, Baker L, Wormald PJ, Tan L. Aspergillus fumigatus biofilm on primary human sinonasal epithelial culture. Am J Rhinol Allergy. 2011;25(4):219-25.

85. Singhal D, Foreman A, Bardy JJ, Wormald PJ. Staphylococcus aureus biofilms: nemesis of endoscopic sinus surgery. Laryngoscope. 2011;121(7):1578-83.

86. Callejas FD, Martinez-Anton A, Alobid I, Fuentes M, Cortijo J, Picado C, RocaFerrer J, Mullol J. Reconstituted human upper airway epithelium as 3D in vitro model for nasal polyposis. PLoS One. 2014;9(6):1-12.
87. Harrington H, Cato P, Salazar F, Wilkinson M, Knox A, Haycock JW, Rose F, Aylott JW, Ghaemmaghami AM. Immunocompetent 3D model of human upper airway for disease modeling and in vitro drug evaluation. Mol Pharm. 2014;11(7):2082-91.

88. Margolis E, Yates A, Levin BR. The ecology of nasal colonization of Streptococcus pneumoniae, Haemophilus influenzae and Staphylococcus aureus: the role of competition and interactions with host's immune response. BMC Microbiol. 2010;10:1-11.

89. Cope EK, Goldstein-Daruech N, Kofonow JM, Christensen L, McDermott B, Monroy F, Palmer JN, Chiu AG, Shirtliff ME, Cohen NA, Leid JG. Regulation of virulence gene expression resulting from Streptococcus pneumoniae and non-typeable Haemophilus influenzae interactions in chronic disease. PLoS One. 2011:6(12):1-9.

90. Kiedrowski MR, Paharik AE, Ackermann LW, Shelton AU, Singh SB, Starner TD, Horswill AR. Development of an in vitro colonization model to investigate Staphylococcus aureus interactions with airway epithelia. Cell Microbiol. 2016;18(5):720-32.

91. Dimova S, Brewster ME, Noppe M, Jorissen A, Augustijns P. The use of human nasal in vitro cell systems during drug discovery and development. Toxicol in Vitro. 2005;19(1):107-22.

92. Morris GE, Bridge JC, Brace LA, Knox AJ, Aylott JW, Brightling CE, Ghaemmaghami AM, Rose FRAJ. A novel electrospun biphasic scaffold provides optimal three-dimensional topography for in vitro co-culture of airway epithelial and fibroblast cells. Biofabrication. 2014;6(3):1-14.

93. Melo E, Kasper JY, Unger RE, Farre R, Kirkpatrick CJ. Development of a bronchial wall model: triple culture on a decellularized porcine trachea. Tissue Eng Part C Methods. 2015;21(9):909-21.

94. Blume C, Reale R, Held M, Millar TM, Collins JE, Davies DE, Morgan H, Swindle EJ. Temporal monitoring of differentiated human airway epithelial cells using microfluidics. PLoS One. 2015;10(10):1-13.

95. Haghi M, Young PM, Traini D, Jaiswal R, Gong J, Bebawy M. Time- and passage-dependent characteristics of a Calu-3 respiratory epithelial cell model. Drug Dev Ind Pharm. 2010;36(10):1207-14.

96. Meindl C, Stranzinger S, Dzidic N, Salar-Behzadi S, Mohr S, Zimmer A, Frohlich E. Permeation of therapeutic drugs in different formulations across the airway epithelium in vitro. PLoS One. 2015;10(8):1-19.

97. Bardet G, Achard S, Loret T, Desauziers V, Momas I, Seta N. A model of human nasal epithelial cells adapted for direct and repeated exposure to airborne pollutants. Toxicol Lett. 2014;229(1):144-9.

98. Clark JG, Kim KH, Basom RS, Gharib SA. Plasticity of airway epithelial cell transcriptome in response to flagellin. PLoS One. 2015;10(2):1-14.

99. Larsen JM, Steen-Jensen DB, Laursen JM, Sondergaard JN, Musavian HS, Butt TM, Brix S. Divergent pro-inflammatory profile of human dendritic cells in response to commensal and pathogenic bacteria associated with the airway microbiota. PLoS One. 2012;7(2):1-10.

100. Li ZG, Levast B, Madrenas J. Staphylococcus aureus downregulates IP-10 production and prevents TH1 cell recruitment. J Immunol. 2017;198(5):1865-74.

101. Kreft ME, Jerman UD, Lasic E, Hevir-Kene N, Rizner TL, Peternel L, Kristan K. The characterization of the human cell line Calu-3 under different culture conditions and its use as an optimized in vitro model to investigate bronchial epithelial function. Eur J Pharm Sci. 2015;69:1-9.

102. Muller L, Brighton LE, Carson JL, Fischer WA, Jaspers I. Culturing of human nasal epithelial cells at the air liquid interface. J Vis Exp. 2013;(80):1-7.

103. Aufderheide M, Forster C, Beschay M, Branscheid D, Emura M. A new computer-controlled air-liquid interface cultivation system for the generation of differentiated cell cultures of the airway epithelium. Exp Toxicol Pathol. 2016;68(1):77-87.

104. Bardet G, Mignon V, Momas I, Achard S, Seta N. Human reconstituted nasal epithelium, a promising in vitro model to assess impacts of environmental complex mixtures. Toxicol in Vitro. 2016;32:55-62.

105. Neilson L, Mankus C, Thorne D, Jackson G, Debay J, Meredith C. Development of an in vitro cytotoxicity model for aerosol exposure using $3 \mathrm{D}$ reconstructed human airway tissue; application for assessment of ecigarette aerosol. Toxicol in vitro. 2015;29(7):1952-62.

106. Reus AA, Maas WJM, Jansen HT, Constant S, Staal YCM, van Triel JJ, Kuper CF. Feasibility of a 3D human airway epithelial model to study respiratory absorption. Toxicol in Vitro. 2014;28(2):258-64.

107. Benam KH, Villenave $\mathrm{R}$, Lucchesi C, Varone A, Hubeau C, Lee HH, Alves SE, Salmon M, Ferrante TC, Weaver JC, Bahinski A, Hamilton GA, Ingber DE. Small airway-on-a-chip enables analysis of human lung inflammation and drug responses in vitro. Nat Methods. 2016;13(2):151. 
108. Baddal B, Muzzi A, Censini S, Calogero RA, Torricelli G, Guidotti S, Taddei AR, Covacci A, Pizza M, Rappuoli R, Soriani M, Pezzicolia A. Dual RNA-Seq of non-typeable Haemophilus influenzae and host cell transcriptomes reveals novel insights into host-pathogen cross talk. MBio. 2015;6(6):1-13.

109. Starner TD, Zhang N, Kim GH, Apicella MA, McCray PB. Haemophilus influenzae forms biofilms on airway epithelia-implications in cystic fibrosis. Am J Respir Crit Care Med. 2006;174(2):213-20.

110. Dunne EM, Toh ZQ, John M, Manning J, Satzke C, Licciardi P. Investigating the effects of probiotics on pneumococcal colonization using an in vitro adherence assay. J Vis Exp. 2014;(86):1-9.

111. Tan NCW, Cooksley CM, Roscioli E, Drilling AJ, Douglas R, Wormald PJ, Vreugde S. Small-colony variants and phenotype switching of intracellular Staphylococcus aureus in chronic rhinosinusitis. Allergy. 2014;69(10):1364-71.

112. Ou JJ, Drilling AJ, Cooksley C, Bassiouni A, Kidd SP, Psaltis AJ, Wormald PJ, Vreugde $S$. Reduced innate immune response to a Staphylococcus aureus small colony variant compared to its wild-type parent strain. Front Cell Infect Microbiol. 2016;6:1-9.

113. Ren DB, Daines DA. Use of the EpiAirway model for characterizing longterm host-pathogen interactions. J Vis Exp. 2011;(55):1-4.

114. Ren DB, Nelson KL, Uchakin PN, Smith AL, Gu XX, Daines DA. Characterization of extended co-culture of non-typeable Haemophilus influenzae with primary human respiratory tissues. Exp Biol Med. 2012;237(5):540-7.

115. Esch EW, Bahinski A, Huh D. Organs-on-chips at the frontiers of drug discovery. Nat Rev Drug Discov. 2015;14(4):248-60.

116. Rahimi R, Htwe SS, Ochoa M, Donaldson A, Zieger M, Sood R, Tamayol A, Khademhosseini A, Ghaemmaghami AM, Ziaie B. A paper-based in vitro model for on-chip investigation of the human respiratory system. Lab Chip. 2016;16(22):4319-25.

117. Libberton B, Horsburgh MJ, Brockhurst MA. The effects of spatial structure, frequency dependence and resistance evolution on the dynamics of toxinmediated microbial invasions. Evol Appl. 2015;8(7):738-50.

118. De Roy K, Marzorati M, Van den Abbeele P, Van de Wiele T, Boon N. Synthetic microbial ecosystems: an exciting tool to understand and apply microbial communities. Environ Microbiol. 2014;16(6):1472-81.

119. Liu CM, Price LB, Hungate BA, Abraham AG, Larsen LA, Chrstensen K, Stegger M, Skov R, Andersen PS. Staphylococcus aureus and the ecology of the nasal microbiome. Sci Adv. 2015;1(5)e1400216:1-7.

120. Fredheim EGA, Flaegstad T, Askarian F, Klingenberg C. Colonisation and interaction between S. epidermidis and S. aureus in the nose and throat of healthy adolescents. Eur J Clin Microbiol Infect Dis. 2015;34(1):123-9.

121. Vandecandelaere I, Depuydt P, Nelis HJ, Coenye T. Protease production by Staphylococcus epidermidis and its effect on Staphylococcus aureus biofilms. Pathog Dis. 2014;70(3):321-31.

122. Frank DN, Feazel LM, Bessesen MT, Price CS, Janoff EN, Pace NR. The human nasal microbiota and Staphylococcus aureus carriage. PLoS One. 2010;5(5):1-15.

123. Tikhomirova A, Trappetti C, Paton JC, Kidd SP. The outcome of H. influenzae and S. pneumoniae inter-species interactions depends on $\mathrm{pH}$, nutrient availability and growth phase. Int J Med Microbiol. 2015;305(8):881-92.

124. Wollenberg MS, Claesen J, Escapa IF, Aldridge KL, Fischbach MA, Lemon KP. Propionibacterium-produced coproporphyrin III induces Staphylococcus aureus aggregation and biofilm formation. MBio. 2014;5(4):1-10.

125. Short FL, Murdoch SL, Ryan RP. Polybacterial human disease: the ills of social networking. Trends Microbiol. 2014;22(9):508-16.

126. De Roy K, Marzorati M, Negroni A, Thas O, Balloi A, Fava F, Verstraete W, Daffonchio D, Boon N. Environmental conditions and community evenness determine the outcome of biological invasion. Nat Commun. 2013;4:1-5.

127. Lijek RS, Weiser JN. Co-infection subverts mucosal immunity in the upper respiratory tract. Curr Opin Immunol. 2012;24(4):417-23.

128. Bosch AATM, Biesbroek G, Trzcinski K, Sanders EAM, Bogaert D. Viral and bacterial interactions in the upper respiratory tract. PLoS Pathog. 2013;9(1):1-12.

129. Marks LR, Davidson BA, Knight PR, Hakansson AP. Interkingdom signaling induces Streptococcus pneumoniae biofilm dispersion and transition from asymptomatic colonization to disease. MBio. 2013;4(4):1-13.

\section{Ready to submit your research? Choose BMC and benefit from:}

- fast, convenient online submission

- thorough peer review by experienced researchers in your field

- rapid publication on acceptance

- support for research data, including large and complex data types

- gold Open Access which fosters wider collaboration and increased citations

- maximum visibility for your research: over $100 \mathrm{M}$ website views per year

At BMC, research is always in progress.

Learn more biomedcentral.com/submissions 